\title{
Overexpression of exogenous biuret hydrolase in rice plants confers tolerance to biuret toxicity
}

\author{
Kumiko Ochiai ${ }^{1}$, Asuka Uesugi ${ }^{1}$, Yuki Masuda ${ }^{1}$, Megumi Nishii ${ }^{1}$, and Toru Matoh ${ }^{1}$ \\ ${ }^{1}$ Kyoto University
}

April 28, 2020

\begin{abstract}
Biuret, a common impurity in urea fertilizers, is toxic to plants, but little is known about the physiological mechanisms underlying its toxicity. Here, we analyzed biuret toxicity in rice (Oryza sativa) plants. We carried out uptake experiments using ${ }^{15} \mathrm{~N}$-labelled biuret and demonstrated that biuret could reach sub millimolar concentrations in rice plants. We also demonstrated that the hydrolysis of biuret in plant cells could confer biuret tolerance to rice plants. This occurred because transgenic rice plants that overexpressed an exogenous biuret hydrolase cloned from a soil bacterium gained improved tolerance to biuret toxicity. Our results indicate that biuret toxicity is not an indirect toxicity caused by the presence of biuret outside the roots, and that biuret is not quickly metabolized in wild-type rice plants. Additionally, it was suggested that biuret was used as an additional nitrogen source in transgenic rice plants, because biuret hydrolase-overexpressing rice plants accumulated more biuret-derived $\mathrm{N}$, as compared to wild-type rice.
\end{abstract}

\section{INTRODUCTION}

Urea, currently the most widely used nitrogen (N) fertilizer worldwide (IFASTAT, https://www.ifastat.org/databases), might contain biuret $\left[\left(\mathrm{CONH}_{2}\right)_{2} \mathrm{NH}\right]$, as a common impurity. Biuret is formed by the thermal condensation of urea. It has been known since the 1950s that excessive amounts of biuret in urea fertilizers cause injury in crops (Jones, 1954; Sanford, Gowing, Young \& Leeper, 1954). A wide range of crops can be potentially affected by biuret toxicity, which often manifests as leaf chlorosis and stunted growth, especially in the young seedling stage (Mikkelsen, 1990). Earlier studies indicated that biuret inhibited protein synthesis inXanthium pensylvanicum leaves (Webster, Verner \& Gansa, 1957) and wheat (Triticum aestivum) germplasms (Ogata \& Yamamoto, 1959). The protein content, however, did not so much decrease in biuret-injured orange (Citrus sinensis ) leaves (Impey \& Jones, 1960). It remains uncertain whether biuret has a direct effect on the protein synthetic machinery. Additionally, ultrastructural analyses showed that changes in chloroplast structure in biuret-injured leaves were similar to those in senescent leaves in grapefruit (Citrus paradise) and orange plants (Achor \& Albrigo, 2005). Moreover, biuret seems to remain unmetabolized in plants, because it was still detected in orange leaves, eight months after foliar spraying was performed (Impey \& Jones, 1960). The exact mechanism underlying biuret toxicity in plants, however, is still far from being understood.

To avoid this hazard, the biuret content in fertilizers is regulated; for example, the upper limit of biuret- $\mathrm{N}$ in urea fertilizer is set at $2 \%$ of the total $\mathrm{N}$ content in Japanese law. Currently, biuret injury has become less frequent in farmers' fields, owing to advances in the technology used for manufacturing urea fertilizers. One method for the fertilization of rice (Oryza sativa) crops involves a single basal application of polymer-coated urea into seedling trays, which improves $\mathrm{N}$ use efficiency and labor efficiency. The extremely high density of coated urea fertilizer adjacent to the roots resulted in biuret toxicity, even though fertilizers that met the official standards were used (Tanahashi, Honda, Takahashi \& Yano, 2003). This illustrates that the risk of biuret toxicity in crops remains latent. 
Certain soil bacteria decompose biuret (Cameron, Durchschein, Richman, Sadowsky \& Wackett, 2011; Esquirol et al., 2018; Jensen \& Schrøder, 1965; Martinez, Tomkins, Wackett, Wing \& Sadowsky, 2001; Robinson, Badalamenti, Dodge, Tassoulas \& Wackett, 2018). One molecule of biuret is converted into three ammonium and two bicarbonate ions via the biodegradation pathway. The first step of biuret degradation is the hydrolysis of biuret into ammonium and allophanate, which is catalyzed by biuret hydrolase (Cameron et al., 2011). Then, allophanate could either undergo spontaneous decarboxylation to form urea under neutral and acidic conditions, or be hydrolyzed further by allophanate hydrolase into ammonium and bicarbonate (Cheng, Shapir, Sadowsky \& Wackett, 2005).

Homologs of biuret hydrolase were detected in a broad range of microorganisms but remained undetected in animals and land plants (Robinson et al., 2018). Although it is not known yet how much biuret plants would take up and accumulate, the introduction of biuret hydrolase from soil bacteria might contribute to biuret detoxification in plant cells. Furthermore, if we could confer the biuret-detoxifying ability to crop plants, biuret could act as a slow-release $\mathrm{N}$ fertilizer and weed controller (Figure S1).

The principal aim of our study is to elucidate the physiological mechanisms underlying biuret toxicity. Additionally, we intend to confer biuret-detoxifying ability to crop plants. Here, we investigated biuret injury in rice plants. We first evaluated biuret uptake in rice plants quantitatively using ${ }^{15} \mathrm{~N}$-labelled biuret. Further, we generated transgenic rice plants that overexpressed bacterialbiuret hydrolase and examined their biuret tolerance.

\section{MATERIALS AND METHODS}

\subsection{Plant materials and growth conditions}

Seeds of Nipponbare, a japonica rice (Oryza sativa) cultivar, were purchased from Nouken Inc. (Kyoto, Japan). Transgenic rice lines overexpressing bacterial biuret hydrolase, which were generated from Nipponbare in this study, were self-pollinated to obtain $T_{1}$ progenies. $T_{1}$ and $T_{2}$ seeds were used for experiments.

Rice plants were grown under hydroponic conditions in a growth chamber (NS-280 FHW; Takayama Seisakusyo, Kyoto, Japan) under a temperature, photo period, and light intensity of $30^{\circ} \mathrm{C}, 12 \mathrm{~h}$, and $350 \mathrm{mmol} \mathrm{m}^{-2}$ $\mathrm{s}^{-1}$, respectively. Rice seeds were soaked in distilled water supplemented with fungicide (Trifumin; Nippon Soda Co., Ltd., Tokyo, Japan) for three days at $30^{\circ} \mathrm{C}$. Ten or twelve of the imbibed seeds were sown on a nylon-mesh $(18$ mesh, $24 \times 36 \mathrm{~mm})$ supported by a plastic frame floating on the culture solution. The culture solution contained $1 \mathrm{mmol} \mathrm{L}{ }^{-1}\left(\mathrm{NH}_{4}\right)_{2} \mathrm{SO}_{4}, 0.25 \mathrm{mmol} \mathrm{L}^{-1} \mathrm{KH}_{2} \mathrm{PO}_{4}, 0.5 \mathrm{mmol} \mathrm{L}-1 \mathrm{KCl}, 0.5 \mathrm{mmol}$ $\mathrm{L}^{-1} \mathrm{CaCl}_{2}, 0.5 \mathrm{mmol} \mathrm{L}-1 \mathrm{MgCl}_{2}, 0.09 \mathrm{mmol} \mathrm{L}-1$ ethylenediamine-N,N,N',N'-tetra acetic acid, iron(III), sodium salt, trihydrate (FeNa-EDTA) and Arnon's micronutrient (cited by Hewitt, 1966). The culture solutions were not aerated, and the solutions were renewed once a week. Seeds that did not germinate were removed from the mesh at an appropriate time. Biuret was included in the culture solution whenever necessary.

\subsection{Measurement of biuret in culture solutions}

Aliquots $(0.94 \mathrm{~mL})$ of the culture solution were mixed with $10 \mu \mathrm{L}$ of $0.5 \mathrm{~mol} \mathrm{~L}^{-1}$ potassium phosphate buffer $(\mathrm{pH} 6.8)$ and $50 \mu \mathrm{L}$ of methanol, and filtered using the Cosmospin Filter G (0.2 $\mu \mathrm{m}$; Nacalai tesque, Kyoto, Japan). A $20-\mu \mathrm{L}$ aliquot of the sample was injected into an HPLC system (LC-10AS, Shimadzu, Kyoto, Japan) equipped with a COSMOSIL 5C18-PAQ column $(5 \mu \mathrm{m}, 4.6 \mathrm{~mm}$ I.D. x $250 \mathrm{~mm}$; Nacalai tesque, Kyoto, Japan). The eluent consisted of $5 \mathrm{mmol} \mathrm{L}^{-1}$ potassium phosphate buffer ( $\mathrm{pH} 6.8$ ) and $5 \%$ (v/v) methanol, and the flow rate was $0.2 \mathrm{~mL} \mathrm{~min}^{-1}$. The absorbance of the eluate was monitored at $210 \mathrm{~nm}$ using a UV detector (SPD-10A, Shimadzu, Kyoto, Japan).

\subsection{Determination of biuret uptake in rice plants}

${ }^{15} \mathrm{~N}$-labelled biuret (biuret- ${ }^{15} \mathrm{~N}_{3}$, [?] 98 atom $\%{ }^{15} \mathrm{~N}$ ) was purchased from Sigma-Aldrich Co (St. Louis, MO, USA). Rice seedlings were raised in the absence of biuret for 17 days. Then, seedlings with uniform sizes were picked from the mesh, and two plants were transferred to a 50-mL glass vial with $40 \mathrm{~mL}$ of culture solution, one day before performing the uptake experiments, to eliminate the possible effects of damaged 
roots. When we used transgenic lines, the presence of the transgene was confirmed beforehand by PCR, using the DNA extracted from leaf blades of the second leaf. Uptake experiments were initiated by the addition of an aliquot of ${ }^{15} \mathrm{~N}$-labeled biuret solution into the vial, to achieve a solution with a final biuret concentration of $0.3 \mathrm{mmol} \mathrm{L}{ }^{-1}$. Plants were allowed to take up ${ }^{15} \mathrm{~N}$-labelled biuret for $48 \mathrm{~h}$. Control plants, to which biuret was not applied, were also grown similarly.

At harvest, roots were rinsed twice in $100 \mathrm{~mL}$ of distilled water (3 minutes each). Plants were separated into shoots and roots, dried in an oven at $70^{\circ} \mathrm{C}$ for two days, and ground into a powder using a ball mill. The $\mathrm{N}$ concentration in plant samples was determined using a CN analyzer (SUMIGRAPH NC-22F, Sumika Chemical Analysis Service, Osaka, Japan). The atom $\%$ of ${ }^{15} \mathrm{~N}$ was determined under contract (Shoko Science Co Ltd, Kanagawa, Japan). Biuret-derived $\mathrm{N}$ content in plant parts were calculated from the ${ }^{15} \mathrm{~N}$ content in samples.

\subsection{Generation of transgenic rice plants overexpressingbiuret hydrolase}

Transgenic Nipponbare plants that over-expressed bacterial biuret hydrolase under the control of the cauliflower mosaic virus 35s promoter were generated. A biuret decomposing soil bacterium,Rhizobium sp. KaB01, which was isolated in this study, was used as a biuret hydrolase donor (see Supporting methods). Insert DNA was amplified from the genomic DNA of KaB01 via PCR, using Prime Star polymerase (Takara Bio, Shiga, Japan) and primers 5'-CACCATGAAGACACTTTCCAGCGC-3' and 5'-TGGCAAATGCCTCTCAAGG$3^{\prime}$. Subcloned PCR products in the vector pENTR/D-TOPO (Life Technologies, Carlsbad, CA) were then transferred to a binary vector pGWB502omega (Nakagawa et al., 2007), via the LR reaction. The transformation of rice was mediated by an agrobacterium, as described by Toki et al. (2006), using theAgrobacterium tumefaciens strain EHA105. The presence of the transgene in regenerated $\mathrm{T}_{0}$ plants was confirmed by PCR, using the Blend Taq polymerase (Toyobo, Osaka, Japan) and primers 5'-ATGAAGACACTTTCCAGCGC3 ' and 5'-TGGCAAATGCCTCTCAAGG-3'.

\subsection{Transgene expression analysis}

Total RNA was extracted from the youngest leaf blade of regenerated $T_{0}$ plants at their vegetative growth stage, using the Plant Total RNA Extraction Miniprep System (Viogene, Taipei, Taiwan). First-strand cDNA was synthesized from total RNA using an oligo dT primer and ReverTra Ace polymerase (Toyobo, Osaka, Japan). Quantitative real-time RT-PCR was performed in duplicate with the TP850 thermal cycler dice real time system single (Takara Bio, Shiga, Japan), using the THUNDERBIRD ${ }^{\circledR}$ SYBR qPCR Mix (Toyobo, Osaka, Japan) and primers 5'-AGCCGATCAAAAAGGTGCTGTC-3' and 5'AATGATATCCCAGCCAGGTTCTCC-3'. The relative expression level was calculated as a ratio to a geometric mean of the expression of ubiquitin and actin. The sequences of primers were $5^{\prime}$-AGAAGGAGTCCACCCTCCACC3' and 5'-GCATCCAGCACAGTAAAACACG-3' for ubiquitin and 5'-ATCCTTGTATGCTAGCGGTCGA$3^{\prime}$ and 5'-ATCCAACCGGAGGATAGCATG-3' for actin.

\subsection{Assay for biuret hydrolase activity}

Crude plant extracts were prepared as described below. Shoots of individual 19-day-old wild-type Nipponbare and transgenic B3-9-1 plants and 16-day-old B2-3-3-3 plants were weighed, and ground into powders under liquid nitrogen using a mortar and pestle. Then, the powdered tissue was homogenized in ten volumes of $25 \mathrm{mmol} \mathrm{L} \mathrm{L}^{-1} 3$-(N-morpholino) propanesulfonic acid (MOPS) buffer ( $\mathrm{pH} \mathrm{8.0).} \mathrm{After} \mathrm{centrifugation,} \mathrm{the}$ supernatant was used for the enzyme assay. Extractions were performed in duplicate for transgenic lines, and in triplicate for wild-type plants.

The biuret hydrolase assay was carried out as described by Martinez et al. (2001). The assay solution contained $50 \mathrm{mmol} \mathrm{L}{ }^{-1}$ sodium phosphate buffer ( $\mathrm{pH} 8$ ), $3 \mathrm{mmol} \mathrm{L}^{-1}$ biuret, and crude cell extracts. The assay mix was incubated at $30^{\circ} \mathrm{C}$, and the reaction was stopped by the addition of $0.5 \mathrm{~mol} \mathrm{~L}^{-1} \mathrm{H}_{2} \mathrm{SO}_{4}$. The amount of ammonia released from biuret was colorimetrically determined by indophenol blue method (Weatherburn, 1967). Protein concentrations were determined by the Bradford method, using Protein Assay CBB Solution (Nacalai tesque, Kyoto, Japan). Measurements were performed in duplicate. 


\subsection{Evaluation of biuret tolerance in transgenic rice plants over expressing biuret hydrolase}

Seeds from each line were sown onto two nylon-mesh floats on the culture solution in the absence of biuret and grown for two days, to achieve uniform germination. Then, one of the two floats were transferred into a new 2-L container that did not contain biuret and the other was transferred into another 2-L container containing $0.3 \mathrm{mmol} \mathrm{L}^{-1}$ biuret. Plants were harvested 7 days after the onset of the biuret treatment. After determining plant heights, leaf blades from the third leaf were used to determine the chlorophyll content, and leaf blades from the second leaf were used for DNA extraction. Chlorophyll was extracted from tissues using $80 \%$ aqueous acetone buffered with $2.5 \mathrm{mmol} \mathrm{L}^{-1}$ sodium phosphate buffer (pH 7.8), and its levels were determined according to the method described by Porra, Thompson \& Kriedmann (1989). The presence of the transgene was confirmed by the PCR method, using Blend Taq polymerase (Toyobo, Osaka, Japan) and the primers 5'-ATGAAGACACTTTCCAGCGC-3' and 5'-TGGCAAATGCCTCTCAAGG-3', and the data for plants not carrying the transgene were omitted from the analysis.

\subsection{Accession}

The sequenced data of Rhizobium sp. KaB01 biuret hydrolasehas been submitted to the DDBJ/EMBL/GenBank databases under the accession number LC532383.

\section{RESULTS}

\subsection{Biuret injury in hydroponically grown rice seedlings}

We first investigated the biuret sensitivity of wild-type rice plants. When wild-type Nipponbare seeds were sown in culture solutions supplemented with varying levels of biuret $\left(0,0.1,0.3\right.$, and $1.0 \mathrm{mmol} \mathrm{L}^{-1}$ biuret), germination was not inhibited, regardless of the biuret levels. The plant height of 7-day-old seedlings decreased with increasing concentrations of biuret (Figure 1a). Chlorosis was observed in some plants exposed to $0.1 \mathrm{mmol} \mathrm{L}{ }^{-1}$ biuret and all plants exposed to $0.3 \mathrm{mmol} \mathrm{L}^{-1}$ biuret. It was most markedly observed in leaf blades of the emerging third leaf. In plants exposed to $1.0 \mathrm{mmol} \mathrm{L}^{-1}$ biuret, chlorosis was less prominent, probably because of the severe reduction in the growth (Figure 1b).

\subsection{Biuret uptake by rice seedlings}

Prior to the evaluation of biuret uptake by rice plants, we first examined biuret decomposition in culture solutions. Containers filled with $1 \mathrm{~L}$ of culture solution supplemented with 0.3 or $1.0 \mathrm{mmol} \mathrm{L}^{-1}$ biuret were placed in the growth chamber, and aliquots of culture solutions were collected from the containers at 0,12 , 24, 48, and $72 \mathrm{~h}$. The biuret concentrations were allowed to remain constant for up to $72 \mathrm{~h}$. This result indicated that biuret was not hydrolyzed in the culture solution within this period.

Then, we carried out 48-h uptake experiments using ${ }^{15} \mathrm{~N}$-labelled biuret. Biuret can be measured as a colored chelation complex with cupric ions or by HPLC analysis combined with UV-detection, which we used for the determination of biuret concentrations in the culture solution. However, the sensitivity of the colorimetry process was too low to determine biuret concentrations in plant samples. Additionally, the peak of biuret could not be separated from UV-absorbing metabolites of rice plants in our system.

When 19-day-old Nipponbare seedlings were allowed to take up ${ }^{15} \mathrm{~N}$-labelled biuret for $48 \mathrm{~h}$, biuret-derived ${ }^{15} \mathrm{~N}$ was detected both in the shoots and roots of the seedlings (Table 1). This result indicated that biuret was taken up by rice roots and possibly translocated into rice shoots. The biuret-derived ${ }^{15} \mathrm{~N}$ concentrations in the shoots and roots were equal to 4.2 and $1.8 \mu \mathrm{mol}$ biuret $\mathrm{g}^{-1} \mathrm{dw}$, respectively. Then, based on the amount of biuret in whole seedlings, the uptake rate of biuret with an external supply of $0.3 \mathrm{mmol} \mathrm{L}^{-1}$ was calculated at $0.5 \mathrm{mmol} \mathrm{mg}^{-1}$ root $\mathrm{DW} \mathrm{h} \mathrm{h}^{-1}$.

\subsection{Transgene expression and biuret decomposing activity in transgenic rice plants}

To examine the effect of biuret hydrolysis in plant cells on the biuret tolerance of rice plants, we generated transgenic rice plants overexpressing biuret hydrolase that were cloned fromRhizobium sp. KaB01. The inserted biuret hydrolase encoded a protein consisting of 238 amino acid residues (Figure S2), whose amino 
acid sequence showed $92 \%$ similarity to a known biuret hydrolase of $R$. leguminosarum bv. viciae 3841 (WP_011654379.1; Cameron et al., 2011). In addition, purified recombinant maltose-binding protein fusion proteins expressed in Escherichia coli showed the biuret decomposing activity (Figure S3). Signal peptides were not detected via the SignalP-5.0 program (Almagro Armenteros et al., 2019), and the protein was predicted to be cytoplasmic localized, using the program PSORTb v.3.0 (Yu et al., 2010).

The biuret hydrolase transgene was expressed in varying levels in regenerated $\mathrm{T}_{0}$ rice leaves, while its expression was not detected in wild-type Nipponbare (Figure 2). Self-pollinated progenies of two independent transgenic lines, B2-3-3 and B3-9-1, which showed high expression levels, were used for further examination.

Crude extracts prepared from 19-day-old seedlings of B2-3-3-3 $\left(\mathrm{T}_{2}\right)$ or 16-day-old seedlings of B3-9-1 $\left(\mathrm{T}_{1}\right)$ showed the biuret decomposing activity. In both lines, the amount of ammonia released from biuret increased linearly with time (Figure 3). The line B3-9-1 showed a higher specific activity than B2-3-3-3. The specific activities of extracts from the B3-9-1 and B2-3-3-3 plants were 8.6 and $0.67 \mathrm{nmol} \mathrm{min}{ }^{-1} \mathrm{mg}^{-1}$ protein, $^{-}$ respectively. Wild-type Nipponbare plants did not exhibit ammonia-releasing activity (Figure 3). Extracts heated at $100^{\circ} \mathrm{C}$ for 5 min were inactive. In addition, extracts prepared from a null segregant of B3-9-1 did not exhibit ammonia-releasing activity. These results indicated that the transgenic rice lines were conferred with biuret decomposing ability by the exogenous biuret hydrolase .

\subsection{Biuret tolerance in transgenic rice plants overexpressingbiuret hydrolase}

Rice plants overexpressing biuret hydrolase showed improved tolerance to biuret (Figure 4). The plant height of 9-day-old wild-type rice seedlings was reduced or remained unchanged with the addition of $0.3 \mathrm{mmol} \mathrm{L}^{-1}$ biuret, though it was significantly increased in two transgenic lines (Table 2). Similar results were also obtained for the chlorophyll content observed in leaf blades of the third leaf. The chlorophyll content in wild-type plants decreased significantly in the presence of excessive biuret levels, but increased in B3-9-1 plants, and remained unchanged in B2-3-3-3 plants (Table 2). These results clearly showed that rice plants overexpressing biuret hydrolasegained tolerance to biuret toxicity through the decomposition of biuret in plants.

\subsection{Biuret uptake in transgenic rice plants}

The increment in plant heights of biuret-treated transgenic lines suggested that biuret was utilized as an additional $\mathrm{N}$ source. Therefore, we also determined biuret uptake in biuret hydrolase -overexpressing lines. The concentration of biuret-derived $\mathrm{N}$ was 2.6 and 5.6 times higher in two transgenic lines, B2-3-3-11 $\left(\mathrm{T}_{2}\right)$ and B3-9-1-5 $\left(\mathrm{T}_{2}\right)$, as compared to that in wild-type plants (Table 3). This suggested that biuret was decomposed in the roots and that ${ }^{15} \mathrm{~N}$ derived from biuret was built into more mobile compounds, such as amino acids, and transported into shoots. Taken together, biuret hydrolaseoverexpressing plants seemingly used biuret as an extra $\mathrm{N}$ source.

\section{DISCUSSION}

Although biuret toxicity in crops is a well-known issue, little is known about the physiology underlying biuret injury. Here, we analyzed for the first time biuret uptake in rice plants quantitatively using ${ }^{15} \mathrm{~N}-$ labelled biuret and revealed that a considerable amount of biuret was taken up by wild-type rice (Table 1). As wild-type rice plants did not show any biuret decomposing activity (Figure 3), biuret-derived ${ }^{15} \mathrm{~N}$ is considered as biuret in plants. Therefore, the shoot biuret concentration is approximately equal to 0.4 mmol L-1 when it is expressed on the basis of the tissue water content. The concentration of biuret was higher in shoots than in roots, which indicates that the amount of biuret retained in roots was small, and that biuret was accumulated in shoots through the transpiration stream. As biuret is a small polar molecule without lipophilic parts, cellular membranes may be slightly permeable to biuret. The rate of biuret uptake was calculated from the ${ }^{15} \mathrm{~N}$ content in whole seedlings, and was found to be equivalent to $0.5 \mu \mathrm{mol} \mathrm{g}{ }^{-1}$ root $\mathrm{dw} \mathrm{h} \mathrm{h}^{-1}$. For comparisons, the rate of urea influx into roots, which is largely mediated by channels and a high-affinity transporter, were about $20 \mu \mathrm{mol} \mathrm{g} \mathrm{g}^{-1}$ root $\mathrm{dw} \mathrm{h}^{-1}$ in Arabidopsis thaliana (Kojima, Bhner, Gassert, Yuan \& von Wirén, 2007) and about $6 \mu \mathrm{mol} \mathrm{g} \mathrm{g}^{-1}$ root $\mathrm{dw} \mathrm{h} \mathrm{h}^{-1}$ in rice (Wang et al., 2012), when 0.3 
mmol L-1 urea was supplied as a sole $\mathrm{N}$ source. The observed uptake rate of biuret was one to two orders of magnitudes lower than that of urea. Similarly, the permeability of biuret could not be detected at $10^{\circ} \mathrm{C}$ in mouse erythrocytes that were permeable to urea (Zhao, Sonawane, Levin \& Yang, 2007). Biuret could possibly move across membranes via simple diffusion. To evaluate biuret accumulation over a prolonged period, we need to develop a method to detect biuret directly. We are currently modifying HPLC methods, to separate biuret from other UV-absorbing compounds in plants.

The overexpression of bacterial biuret hydrolase conferred biuret tolerance to rice plants (Figure 4, Table 2 ). Conversely, biuret was seemingly not metabolized, or very slowly metabolized in wild-type rice plants. This is consistent with our enzyme assay results, obtained using leaf crude extracts (Figure 3), and with the previous report on biuret in orange leaves, in which biuret was detected by the eight months after foliar application by a qualitative analysis (Impey \& Jones, 1960). The lack of an efficient decomposition pathway is probably responsible for biuret accumulation and toxicity in rice plants. Besides, biuret tolerance conferred by the biuret hydrolase suggested that an injury in rice plants occurred because of the direct effects of biuret within plants, but not from the indirect effects of biuret outside roots.

Additionally, our results on the biuret injury in wild-type rice plants gave some indications of mechanisms underlying biuret toxicity. In wild-type rice seedlings, a biuret concentration of $0.1 \mathrm{mmol} \mathrm{L}^{-1}$ and above in the culture solution caused a significant reduction in the growth (Figure 1). It was roughly consistent with the toxic concentration of biuret reported for hydroponically grown naked barley (Funabiki Ogata \& Sakamoto, 1956) and pot cultured young citrus and avocado plants (Haas \& Brusca, 1954). The rather high dose, together with the significant accumulation of biuret in rice shoots, suggests that biuret is moderately toxic and that biuret might have a weak affinity with its target. The occurrence of leaf chlorosis was observed, along with growth inhibition, in biuret-injured rice seedlings (Figure 1). The colorless appearance of elongating young leaves indicates that chloroplast development was impaired by excessive biuret levels. Closely similar patterns of chlorosis were often observed in rice seedlings exposed to cold stress (Yoshida, Kanno, Sato \& Kameya, 1996). It has been shown that cold stress especially impairs the establishment of the plastid genetic system, during chloroplast development in rice seedlings (Kusumi et al., 2011). Although the mechanism by which it occurs is yet to be verified, biuret in leaves might trigger similar downstream cellular responses. On the other hand, we have found that biuret causes growth inhibition even in heterotrophic suspension cells of rice (unpublished data). Hence, biuret probably inhibits other basic metabolic processes as well. To have a better understanding of the mechanism of biuret injury, we are planning to analyze changes in transcript and metabolite levels in rice cells under biuret toxicity.

The findings reported here clearly demonstrate that it is possible to confer biuret detoxification ability on rice plants by introducing the microbial biuret hydrolase (Figure 4, Table 2). Moreover, rice plants overexpressing biuret hydrolase utilize ammonium- $\mathrm{N}$ produced by the hydrolysis of biuret in plant cells as an additional $\mathrm{N}$ source (Table 3). In soil, the decomposition rate, or the mineralization rate, of biuret is slower than that of urea (Ogata \& Funabiki, 1956; Sahrawat, 1981). Taken together, when biuret is applied as a N fertilizer to the transgenic rice lines that were generated here, the fertilizer use efficiency would possibly be improved compared with that of urea fertilization. We are currently working on soil-culture experiments to evaluate the effect of biuret as a $\mathrm{N}$ fertilizer.

\section{ACKNOWLEDGEMENTS}

This work was supported in part by JSPS KAKENHI Grant Number JP19K05755.

\section{CONFLICT OF INTEREST STATEMENT}

There are no conflicts of interest to declare.

\section{AUTHOR CONTRIBUTIONS}

K.O. and T.M. conceived and designed the study and supervised the experiments. A.U. performed most of the experiments. Y.M. isolated the soil bacterium. K.O. and M.N. contributed to the preliminary experiments. K.O. wrote the manuscript. All authors contributed to the writing of the manuscript. 


\section{REFERENCES}

Achor D.S. \& Albrig L.G. (2005). Biuret toxicity symptoms in citrus leaves mimics cell senescence rather than nutritional deficiency chlorosis. Journal of the American Society for Horticultural Science, 130, 667-673.

Almagro Armenteros J.J., Tsirigos K.D., Sønderby C.K., Petersen T.N., Winther O., Brunak S., von Heijne G. \& Nielsen H. (2019). SignalP 5.0 improves signal peptide predictions using deep neural networks. Nature Biotechnology, 37, 420-423.

Cameron S.M., Durchschein K., Richman J.E., Sadowsky M.J. \& Wackett L.P. (2011). New family of biuret hydrolases involved in $s$-Triazine ring metabolism. ACS catalysis, 1,1075-1082.

Cheng G., Shapir N., Sadowsky M.J. \& Wackett L.P. (2005). Allophanate hydrolase, not urease, functions in bacterial cyanuric acid metabolism. Applied and Environmental Microbiology, 71, 4437-4445.

Esquirol L., Peat T.S., Wilding M., Lucent D., French N.G., Hartley C.J., Newman J. \& Scott C. (2018). Structural and biochemical characterization of the biuret hydrolase (BiuH) from the cyanuric acid catabolism pathway of Rhizobium leguminasorum bv. viciae3841. PLOS ONE, 13, e0192736.

Funabiki S., Ogata T. \& Sakamoto T. (1956). Studies on biuret from agricultural standpoint: I. Influences on plant growth. The Scientific Reports of The Matsuyama Agricultural College, 12, 1-14.

Haas A.R.C. \& Brusca J.N. (1954). Biuret, toxic form of nitrogen: Soluble nitrogen compounds are not of equal value as fertilizers as shown by tests with citrus and avocado. California Agriculture , 8, 7-11.

Hewitt E.J. (1966). The composition of the nutrient solution. In Sand and Water Culture Methods Used in the Study of Plant Nutrition (eds E. J. Hewitt), pp 190. Farnham Royal Bucks, Commonwealth Agricultural Bureaux, Slough, UK.

Impey R.L. \& Jones W.W. (1960). Effects of biuret on nitrogen status of Washington navel and Valencia orange leaves. American Society for Horticultural Science, 76, 186-192.

Jensen H.L. \& Schrøder M. (1965). Urea and biuret as nitrogen sources for Rhizobium Spp. Journal of Applied Bacteriology, 28,473-478.

Jones W.W. (1954). Biuret toxicity of urea foliage sprays on citrus.Science, 120, 499-500.

Kojima S., Bohner A., Gassert B., Yuan L. \& von Wirén N. (2007). AtDUR3 represents the major transporter for high-affinity urea transport across the plasma membrane of nitrogen-deficient Arabidopsis roots. Plant Journal, 52, 30-40.

Kusumi K., Sakata C., Nakamura T., Kawasaki S., Yoshimura A. \& Iba K. (2011). A plastid protein NUS1 is essential for build-up of the genetic system for early chloroplast development under cold stress conditions.Plant Journal, 68, 1039-1050.

Martinez B., Tomkins J., Wackett L.P., Wing R. \& Sadowsky M.J. (2001). Complete nucleotide sequence and organization of the Atrazine catabolic plasmid pADP-1 from Pseudomonas sp. Strain ADP.Journal of Bacteriology, 183, 5684-5697.

Mikkelsen R.L. (1990). Biuret in urea fertilizer. Fertilizer research, 26, 311-318.

Nakagawa T., Suzuki T., Murata S., Nakamura S., Hino T., Maeo K., Tabata R., Kawai T., Tanaka K., Niwa Y., Watanabe Y., Nakamura K., Kimura T. \& Ishiguro S. (2007). Improved Gateway binary vectors: High-performance vectors for creation of fusion constructs in transgenic analysis of plants. Bioscience, Biotechnology, and Biochemistry, 71,2095-2100.

Ogata, T. \& Funabiki, S. (1956) Studies on biuret from agricultural standpoint: II. Stability of biuret in soil. The Scientific Reports of The Matsuyama Agricultural College, 12, 15-22. 
Ogata T. \& Yamamoto M. (1959). Effects of biuret on the metabolism of germinating plant. I. Japanese Journal of Soil Science and Plant Nutrition, 29, 549-555. (in Japanese )

Porra R.J., Thompson W.A. \& Kriedemann P.E. (1989). Determination of accurate extinction coefficients and simultaneous equations for assaying chlorophylls $a$ and $b$ extracted with four different solvents: verification of the concentration of chlorophyll standards by atomic absorption spectroscopy. Biochimica et Biophysica Acta (BBA) - Bioenergetics, 975, 384-394.

Robinson S.L., Badalamenti J.P., Dodge A.G., Tassoulas L.J. \& Wackett L.P. (2018). Microbial biodegradation of biuret: defining biuret hydrolases within the isochorismatase superfamily. Environmental Microbiology, 20, 2099-2111.

Sanford W.G., Gowing D.P., Young H. Y. \& Leeper R.W. (1954) Toxicity to pineapple plants of biuret found in urea fertilizers from different sources. Sicence, 120, 349-350.

Sahrawat, K.L. (1981) Mineralization of biuret nitrogen in soil.Plant and Soil, 62, 46-471.

Tanahashi T., Honda M., Takahashi K. \& Yano H. (2003). Analysis of chlorosis caused by resin-coated urea used in nursery bed for paddy-rice. Japanese Journal of Soil Science and Plant Nutrition, 74, 219-222. (in Japanese )

Toki S., Hara N., Ono K., Onodera H., Tagiri A., Oka S. \& Tanaka, H. (2006). Early infection of scutellum tissue with Agrobacterium allows high-speed transformation of rice. Plant Journal, 47, 969-976.

Wang W.H., Köhler B., Cao F.Q., Liu G.W., Gong Y.Y., Sheng S., Song Q.C., Cheng X.Y., Garnett T., Okamoto M., Qin R., Muelloer-Roeber B., Tester M. \& Liu L.H. (2012). Rice DUR3 mediates high-affinity urea transport and plays an effective role in improvement of urea acquisition and utilization when expressed in Arabidopsis . New Phytologist, 193, 432-444.

Weatherburn M.W. (1967). Phenol-hypochlorite reaction for the determination of ammonia. Analytical Chemistry,39:971-974.

Webster G.C., Verner R.A. \& Gansa A.N. (1957). The effect of biuret on protein synthesis in plants. Plant Physiology, 32, 60-61.

Yoshida R., Kanno A., Sato T. \& Kameya T. (1996). Cool-temperature-induced chlorosis in rice plants. I. Relationship between the induction and a disturbance of etioplast development.Plant Physiology, 110, 997-1005.

Yu N.Y., Wagner J. R., Laird M. R., Melli G., Rey S., Lo R., Dao P., Sahinalp S.C., Ester M., Foster L.J. \& Brinkman F.S. (2010). PSORTb 3.0: improved protein subcellular localization prediction with refined localization subcategories and predictive capabilities for all prokaryotes. Bioinformatics, 26, 1608-1615.

Zhao D., Sonawane N.D., Levin M.H. \& Yang B. (2007). Comparative transport efficiencies of urea analogues through urea transporter UT-B.Biochimica et Biophysica Acta - Biomembranes, 1768,1815-1821.

\section{FIGURE LEGENDS}

FIGURE 1 Symptoms of biuret toxicity in rice plants. Rice seedlings were hydroponically grown in a culture solution supplemented with $0,0.1,0.3$, and $1.0 \mathrm{mmol} \mathrm{L}^{-1}$ biuret. (a) Plant heights of 7-day-old seedlings. The data represent means $\pm \mathrm{SD}(\mathrm{n}=22-24)$. Different alphabets indicate significant differences between groups $(p<0.05$, Tukey test). (b) Representative images of 7 -day-old seedlings.

FIGURE 2 Relative expression levels of biuret hydrolasein transgenic rice plants.

The expression in the youngest leaf at the vegetative growth stage was determined via real-time PCR. Ubiquitin and Actin1 were used as internal standards for normalization. The values are means of two technical replicates. In names of transgenic lines, the combination of the first and second numbers indicates a callus derived from a single seed, and the third number indicates an individual plant regenerated from the callus. 
FIGURE 3 Biuret-decomposing activities of crude extracts of rice plants.

Crude extracts were prepared from shoots of individual 19-day-old wild-type Nipponbare (solid boxes, $\mathrm{n}=3$ ) and transgenic B3-9-1 (solid circles, $n=2$ ) plants and 16-day-old B2-3-3-3 (open circles, $n=2$ ). Extracts were incubated at $30^{\circ} \mathrm{C}$ with $50 \mathrm{mmol} \mathrm{L}-1$ sodium phosphate buffer $(\mathrm{pH} 8)$ and $3 \mathrm{mmol} \mathrm{L} \mathrm{L}^{-1}$ biuret. The reaction was stopped by adding $0.5 \mathrm{~mol} \mathrm{~L}^{-1} \mathrm{H}_{2} \mathrm{SO}_{4}$. The amount of ammonia released from biuret was determined using indophenol blue. The data represent means $\pm \mathrm{SD}$.

FIGURE 4 Biuret tolerance of a transgenic rice line overexpressing exogenous biuret hydrolase. Biuret treatment $(0$ and $0.3 \mathrm{mmol} \mathrm{L}-1)$ was started two days after the sowing process. Photos were taken 9 days after sowing. Wild-type rice plants (left panel) and transgenic rice plants (line B2-3-3-3, right panel) grown without and with biuret.

Table $1{ }^{15} \mathrm{~N}$-Biuret uptake in rice plants. Nineteen-day-old Nipponbare seedlings were exposed to $0.3 \mathrm{mmol}$ $\mathrm{L}^{-1}{ }^{15} \mathrm{~N}$-biuret for $48 \mathrm{hr}$. Two plants were maintained in a $40-\mathrm{mL}$ vial. Values are expressed as means $\pm \mathrm{SD}$ $(\mathrm{n}=3)$.

Dry weight Total-N Biuret-derived N

$\left(\mathrm{mg} \mathrm{vial}{ }^{-1}\right)\left(\mathrm{mmol} \mathrm{g}^{-1} \mathrm{DW}\right)\left(\mu \mathrm{mol} \mathrm{g} \mathrm{g}^{-1} \mathrm{DW}\right)\left(\mu \mathrm{mol} \mathrm{vial}{ }^{-1}\right)$

Shoots $124 \pm 3.882 .43 \pm 0.0913 .5 \pm 1.021 .67 \pm 0.18$

Roots $23.8 \pm 1.061 .75 \pm 0.015 .83 \pm 0.550 .13 \pm 0.01$

Table 2 Plant height and chlorophyll content of overexpressing wild-type (WT) and biuret hydrolase rice plants under the effect of biuret toxicity. Biuret treatment $\left(0.3 \mathrm{mmol} \mathrm{L} \mathrm{L}^{-1}\right)$ was started two days after sowing, and nine plants were harvested. Two transgenic lines, B3-9-1 and B2-3-3-3, were grown in separate experiments. Values are expressed means $\pm \mathrm{SD}$.

Line Biuret Plant height Chlorophyll content Number of

$\left(\mathrm{mmol} \mathrm{L}^{-1}\right)(\mathrm{cm})(\mu \mathrm{g} / \mathrm{mg} \mathrm{FW})$ plants

WT $018.9 \pm 1.053 .43 \pm 0.1916$

$0.318 .2 \pm 1.40$ n.s. $1.81 \pm 1.10 * 13$

B3-9-1 $019.3 \pm 1.143 .10 \pm 0.3116$

$0.320 .5 \pm 1.10 * 3.46 \pm 0.28 * 12$

WT $019.0 \pm 1.392 .80 \pm 0.2712$

$0.316 .3 \pm 2.18 * 1.01 \pm 0.80 * 12$

B2-3-3-3 $019.3 \pm 1.292 .89 \pm 0.3916$

$0.320 .3 \pm 1.41 * 3.14 \pm 0.41$ n.s. 16

Asterisks indicate significant differences between biuret treatments $(p<0.05$, Student's t-test).

n.s.: not significant

Table 3 Biuret-derived ${ }^{15} \mathrm{~N}$ in shoots of biuret hydrolase overexpressing rice plants. Nineteen-day-old seedlings were exposed to $0.3 \mathrm{mmol} \mathrm{L}{ }^{-115} \mathrm{~N}$-biuret for $48 \mathrm{hr}$. Two plants were maintained in a $40-\mathrm{mL}$ vial. Values are expressed means $\pm \mathrm{SD}$ (WT: $\mathrm{n}=2$, B2-3-3-11 and B3-9-1-5: $\mathrm{n}=3$ ).

Dry weight Total-N Biuret-derived N

$\left(\mathrm{mg} \mathrm{vial}^{-1}\right)\left(\mathrm{mmol} \mathrm{g}^{-1} \mathrm{DW}\right)\left(\mu \mathrm{mol} \mathrm{g}{ }^{-1} \mathrm{DW}\right)\left(\mu \mathrm{mol} \mathrm{vial}{ }^{-1}\right)$

WT $109^{\mathrm{b}} \pm 11.22 .30^{\mathrm{a}} \pm 0.1316 .4^{\mathrm{a}} \pm 1.761 .80^{\mathrm{a}} \pm 0.38$ 
B2-3-3-11 76.2 $\pm 6.672 .35^{\mathrm{a}} \pm 0.2142 .3^{\mathrm{b}} \pm 5.393 .20^{\mathrm{b}} \pm 0.13$

B3-9-1-5 77.6 a $^{\mathrm{a}} 5.792 .42^{\mathrm{a}} \pm 0.1291 .4^{\mathrm{c}} \pm 1.987 .09^{\mathrm{c}} \pm 0.59$

Different alphabets indicate significant differences between rice lines $(p<0.05$, Tukey's test).

(a)

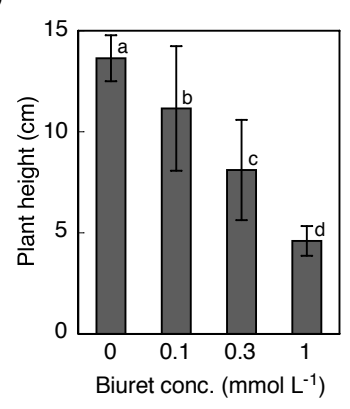

(b)

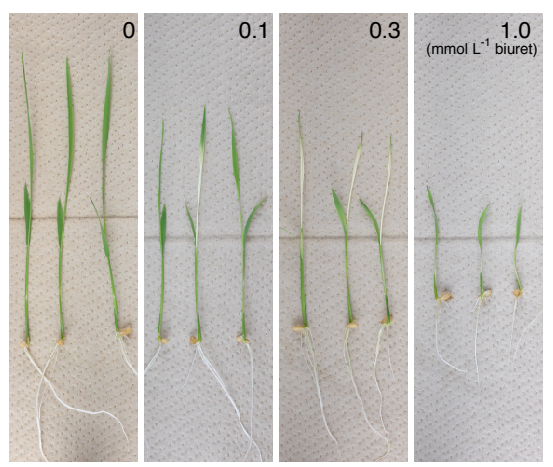

Fig.1

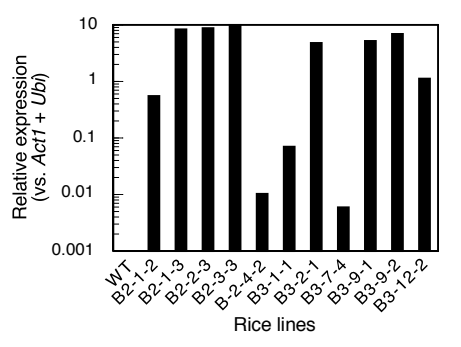

Fig. 2 


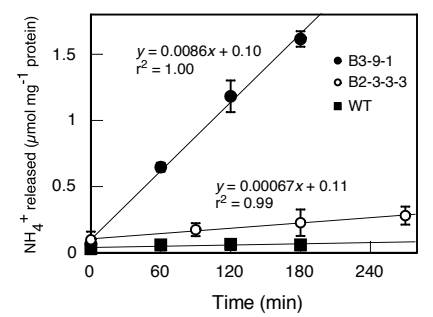

Fig. 3

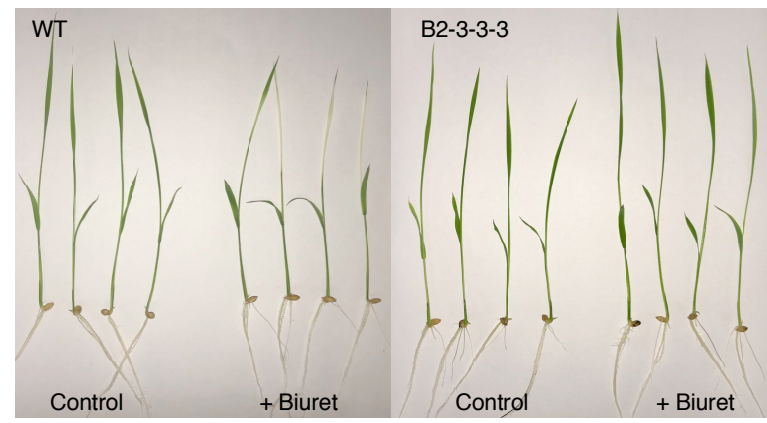

Fig. 4 